\title{
Micharmut: Más allá de la vanguardia
}

\author{
Álvaro M. Pons \\ Universitat de València
}

\begin{abstract}
Álvaro M. Pons (Barcelona, 1966). Doctor en Física y Profesor Titular de Universidad en la Universitat de València. Realiza labores de crítica de cómics desde 1989, colaborando con publicaciones como El maquinista, Volumen, Guía del cómic, Trama, Cartelera Turia o El País. Ha comisariado exposiciones, colaborado en diversas publicaciones académicas nacionales e internacionales y es autor del libro Viñetas a la Luna de Valencia (2007).
\end{abstract}




\section{Introducción}

Analizar la trayectoria artística de Juan Enrique Bosch "Micharmut" (Valencia, 1953) lleva de forma obligada a una paradoja: tras casi cuarenta años en activo, su obra consigue resaltar por una coherencia inédita que se plasma en cualquier argumentación que se construya, desde la estilística a la propia filosofía inherente al discurso creativo del autor, pasando por supuesto por unos anclajes en la tradición historietística reconocidos y reivindicados continuamente. Sin embargo, ese análisis será siempre superficial: la obra de Micharmut consigue romper todas las fronteras existentes en el medio dejando las herramientas de evaluación invalidadas desde el primer momento, resistiéndose con rebeldía a cualquier categorización que no termine creando una concreta y específica para él, delimitada estrictamente alrededor de su obra y sin posibilidad de encontrar nexos que la propongan como un camino abierto que han podido transitar otros autores. Micharmut ha creado un estilo tan fascinante en su complejidad que tan solo puede ser seguido por él mismo, favoreciendo una imagen de hermetismo que ha transformado su obra en objeto de culto y, simultáneamente, a él en el paradigma del autor maldito.

El acercamiento a su obra es, forzosamente, una experiencia personal intransferible: cualquier intento de estudio ajeno desde una búsqueda del habitual consenso que precisa el debate académico será infructuoso desde el momento en que se plantee, condenado a un fracaso indefectible e inapelable ante la única realidad palpable: La obra de Micharmut es, más allá de un mundo de ficción personal, una experiencia lectora que precisa de una interpretación que solo puede nacer desde la interiorización de una propuesta que no duda en quebrar los conceptos básicos del lenguaje de la historieta.

\section{La influencia del entorno: del fanzine como rebeldía ética y estética}

La formación autoral de Micharmut se produce en un momento convulso de la historia de España: los años 70 suponen desde el punto de vista de la historieta un periodo de agitación efervescente, ${ }^{1}$ en el que las influencias que llegan tanto desde Europa como desde los EE. UU. animan a los jóvenes autores españoles a utilizar la historieta como vehículo de un discurso transgresor contracultural que, en el caso español, alberga importantes diferencias con sus coetáneos. La aparición del movimiento underground americano y de la nueva consideración del cómic adulto en Francia aprovechan precisamente la percepción del cómic como medio infantil para establecer un discurso de provocación y desacato a las posición culturales establecidas. En Francia, el cómic de autor se convierte en uno de los elementos básicos de una rebelión sociocultural que demanda un cambio de la ética imperante. Las obras de Jean Claude Forest, Guy Pellaert o Nicolas Devil sorprenden a los lectores de la época transformando un lenguaje considerado infantil en el medio de una denuncia política enfundada en una apariencia de erotismo libertario, que bebe directamente de las vanguardias artísticas más radicales, desde el pop-art a la figuración narrativa. ${ }^{2}$ Toda una rebelión contra el orden establecido que no pasa desapercibida a los críticos y semióticos más importantes de los años 60, como Lacassin o Eco, que abanderaron todo un movimiento intelectual de reivindicación y renovación de la historieta. ${ }^{3}$

La situación americana no deja de tener el mismo sentido: la oposición a la cultura tradicional desde un medio considerado como infantil, desde posiciones de extrema experimentación y provocación con autores como Robert Crumb, Spain Rodríguez, Gilbert Shelton o Víctor Moscoso. Pero mientras el movimiento francés tendría acomodo en unos formatos de edición similares a los de la literatura o arte (con libros de gran calidad o en revistas para adultos, alejándose de la tradicional revista infantil), el

\footnotetext{
1 Dopico, P. El cómic underground español, 1970-1980. Madrid, Cátedra, 2005.

2 Pons, Á. "Ciencia ficción y erotismo para un cómic adulto europeo". Quaderns de filología.Estudis literaris, 14, 31-45, 2009.

3 Coma, J. El ocaso de los héroes en los cómics de autor. Barcelona. Edicions 62, 1984.
} 
modelo americano utilizaría fundamentalmente el formato de comic-book, realzando el contraste con las publicaciones comerciales al uso de los años $60 .{ }^{4}$

En España la situación es radicalmente diferente: pese a estar viviéndose los últimos estertores de la dictadura franquista, el movimiento contestatario no puede definirse como contracultural, sino directamente como reivindicativo de las libertades democráticas de las que carecía el pueblo español. Frente a la reivindicación de progreso social que se hacía en Francia o en EE. UU., en España se estaba directamente demandando la llegada de un cambio político que se tradujera en democracia y libertad. El cómic era un medio considerado infantil por el régimen y la censura erradicaba cualquier intento de emancipación de la historieta fuera de los cánones establecidos. ${ }^{5}$ Una historieta de reivindicación de libertades no era una provocación social como ocurría en sus homólogos franceses o americanos, era un delito perseguido por el régimen. En una atmósfera represiva y peyorativa hacia la historieta, las influencias de estos dos movimientos llegarán a toda una generación de jóvenes autores tanto a través de la importación subterránea de los originales como, fundamentalmente, de dos publicaciones que romperían esquemas y se atreverían a lidiar continuamente con el secuestro administrativo y la persecución: Mata Ratos y Star. La primera tomaba como referente el modelo francés de Hara-Kiri, mientras que la segunda introduce la cultura underground americana publicando historietas de Crumb. Estas publicaciones impactarían de forma decisiva en grupos de jóvenes autores catalanes, que pronto se organizarían en fanzines como El Rrollo Enmascarado, con una clara influencia del underground americano tanto en estilo como en contenidos, de la que solo se apartaba el valenciano Javier Errando Mariscal, con una participación festiva y humorística con un grafismo más próximo al de los dibujos animados o la historieta clásica infantil valenciana que al del underground.

Estas diferencias serán claves para entender la distinta singladura de los grupos de historieta asentados en Barcelona y la de los grupos que aparecieron en Valencia en la misma época. ${ }^{6}$ Precisamente en el año 1975 Sento Llobell (que firma Dau-Dau) y Juan Enrique Bosch (que firma por entonces como Mitjarmut) publican Ademuz Km.6, un fanzine que define claramente estas diferencias. Los dos estudiantes de Bellas Artes conmemoraban con este cuadernillo el primer concierto de rock que se realiza en la capital valenciana, usando la historieta no como un medio reivindicativo como en las publicaciones del grupo del Rrollo, sino con una clara vocación testimonial - festivo - costumbrista de lo acontecido en el concierto, usando un estilo más deudor de los delirios pop de los 60 que del más rudo underground americano. Una dependencia que queda además confirmada en la historieta colectiva Retallat-Pegat, en la que se hace un repaso a los principales iconos de los años 50 y 60 , desde Pumby y Superman a la Coca-Cola y los Beatles, pero también de los acontecimientos políticos más importantes del momento. Estas diferencias no se pueden explicar tan solo por el tópico del festivo y luminoso carácter mediterráneo, sino que hay que rastrear los orígenes de esta estética en los movimientos artísticos de la Valencia de finales de los 60, que tenían precisamente en la vanguardia del pop americano su principal fuente de inspiración. Equipos de artistas valencianos como el Equipo Crónica o el Equipo Realitat'son ejemplos perfectos de esta reivindicación de la iconografía de la publicidad como elemento discursivo del arte, formando una corriente de una tremenda vitalidad, que tendría en nombres como Solbes, Valdés, Armengol, Gassent o Heras a sus máximos exponentes. El diseño gráfico y el diseño industrial se alzan como catalizadores de esta nueva forma de plantear el arte desde una perspectiva más urbana, enraizada en la sociedad de consumo, en un movimiento colectivo que afecta a casi todas las disciplinas artísticas que se desarrollan en Valencia. Es lógico pensar que estos movimientos artísticos resultarán especialmente influyentes en unos autores de historietas que, justo en ese momento, están todavía en sus

\footnotetext{
${ }^{4}$ García, S. La novela gráfica. Bilbao. Astiberri, 2010.

5 VÁzQuez de PARga, S. Los cómics del franquismo. Barcelona, Planeta, 1980.

6 Pons, Á., Porcel, P. y Sorní, V. Viñetas a la luna de Valencia. Onil, Edicions de Ponent, 2007.
}

7 Ambos equipos no solo utilizaron elementos del cómic como parte de su discurso artístico. A principios de los años 70 aceptaron el encargo de realizar una serie de cómics sobre diferentes temáticas (vidas de personajes ilustres, género de agentes secretos...) en los que plasmaron su estilo puramente pop. Por desgracia, estas historias siguen inéditas, aunque parte de sus originales, que se conservan íntegramente en el Instituto Valenciano de Arte Moderno, han podido ser vistos en exposiciones. 
primeras etapas formativas como artistas. En ese sentido, hay que destacar en estos dos autores dos influencias más: por un lado, la de su formación lectora infantil, en la que autores como Urda, Palop, Benejam, Coll u Opisso marcarán definitivamente su interés estético. Por otro, la influencia decisiva de Miguel Calatayud (Aspe, 1942), un dibujante alicantino asentado en Valencia que representa en ese momento una fresca renovación de los anquilosados planteamientos de la historieta infantil, rompiendo el esquema tradicional de dibujo académico (tanto en su vertiente infantil como realista) para asimilar de forma abierta y decidida otros planteamientos más modernos que llegan desde discursos pictóricos de vanguardia o las nuevas corrientes de la psicodelia que puedan representar autores como Peter Max, Heinz Edelmann o Milton Glasser.

La aparición de este fanzine actúa como catalizador para la eclosión de una intensa actividad creativa alrededor de otras publicaciones como El Gat Pelat, dirigido por Manel Gimeno y con colaboraciones de lo que sería el germen de la que más tarde sería llamada la "Nueva Escuela Valenciana", de la que Micharmut formaría parte sustancial.

Sin embargo, se puede establecer el verdadero nacimiento de Micharmut apenas un año más tarde con la aparición del sello Els tebeus del cingle, una clara transposición del modelo desarrollado en Barcelona con Los tebeos del Rrollo que desde el primer momento demuestra un espíritu formal similar pero muy alejado en sus presupuestos, buscando un discurso distintivo que vendría precisamente de la mano de Micharmut. Bzzz (1977) sería la primera monografía del grupo, un cuadernillo grapado de veinte páginas en las que el autor se lanza a una experimentación radical en lo que se puede perfectamente considerar como el primer paso de un camino de renovación e investigación constante. Micharmut deja de lado por completo los cánones del movimiento underground que se mueve en Cataluña para explorar las posibilidades del medio desde la tradición historietística previa. Fija su mirada en autores como Coll, Palop o Benejam ${ }^{8}$ para expandirlas con la mirada propuesta en la vanguardia estética que se desarrolla

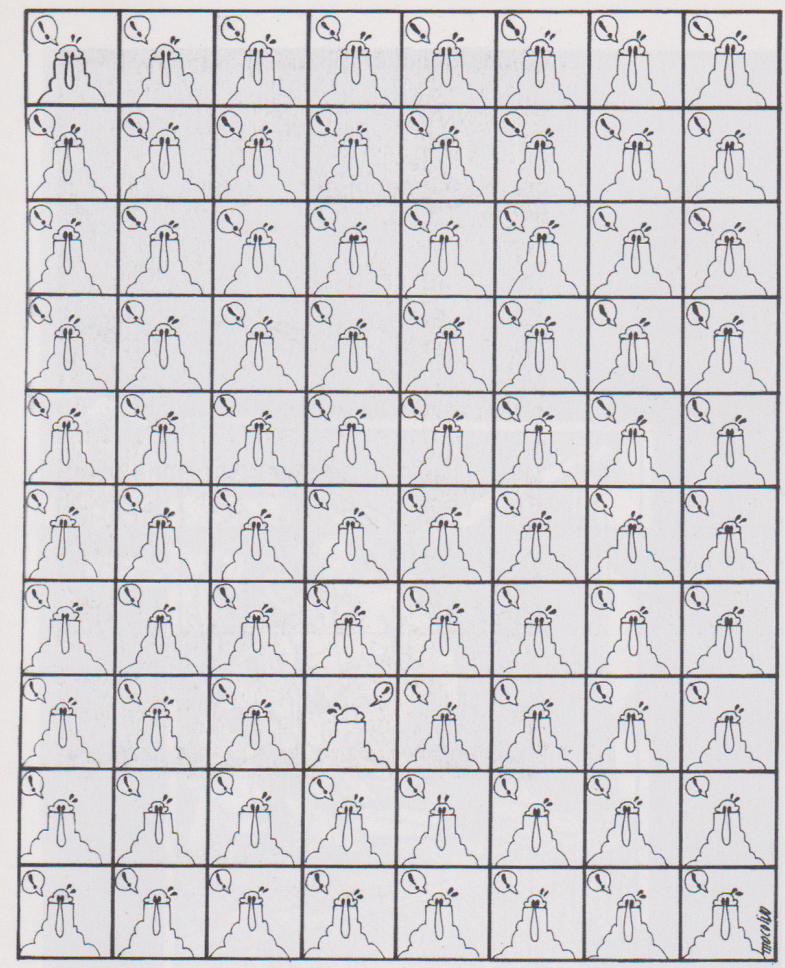

FIG. 1. Ejemplo de historieta experimental publicada en $B z z z$ (1977). El estilo repetitivo recuerda a los planteamientos formales de OuBaPo.

\footnotetext{
8 Coll y Benejam son integrantes clásicos de la plantilla de dibujantes de TBO. El primero realizaba historias cortas de humor absurdo con estilo que se puede entroncar en la línea clara, mientras que el segundo fue el creador de la famosa serie "La familia Ulises". Palop trabajó tanto para Pumby como Jaimito, siendo algunas de sus más famosas creaciones "Bartolo, as de los vagos" o "Payasete y Fu-Chi-Nin".
} 
a su alrededor. Una fusión de respeto a la tradición y de absoluta radicalidad en la búsqueda de nuevos espacios que se adelanta casi en veinte años al de Chris Ware, posiblemente el autor más renovador del lenguaje del cómic cuyo trabajo nace de un discurso de planteamientos idénticos. Sirva como ejemplo de hasta qué punto se avanza Micharmut a su tiempo que encontraremos en sus páginas una propuesta que entronca claramente con el movimiento OuBaPo que nacería en Francia en los años 90.

\section{El paso a la profesionalidad: de Valencia a El Cairo}

La apertura democrática que se vive a finales de los 70 tras la muerte del dictador permite que la contraculturalidad que vivía marginada en la clandestinidad consiga salir a la luz a través de diferentes publicaciones. La pionera Star será pronto seguida por un seguido de publicaciones como TOTEM, 1984 o El Víbora que darán acogida y presencialidad a una forma diferente de entender el cómic como medio plenamente adulto. A imagen y semejanza de lo que ocurre en Francia, el cómic comienza a ocupar espacios de respeto social y cultural que lo aleja del gueto infantil y lo acerca a la atención de un público diferente y distinto. ${ }^{9}$ Una nueva vitalidad que necesita de nuevos autores jóvenes, que no vengan de la tradición de historieta infantil clásica de los 60 sino preparados para nuevas formas de entender el medio, tanto estéticas como en contenidos. Un llamamiento que tendrá respuesta en diferentes colectivos, como los autores que trabajaban para el mercado americano en las revistas adultas de Warren, ${ }^{10}$ pero sobre todo en los jóvenes autores involucrados en los movimientos underground. Evidentemente, la generación de autores valencianos formada alrededor de los fanzines será protagonista necesaria de esta nueva etapa. Así Daniel Torres comienza a publicar en El Víbora, mientras Manel Gimeno y Sento Llobell en Bé-

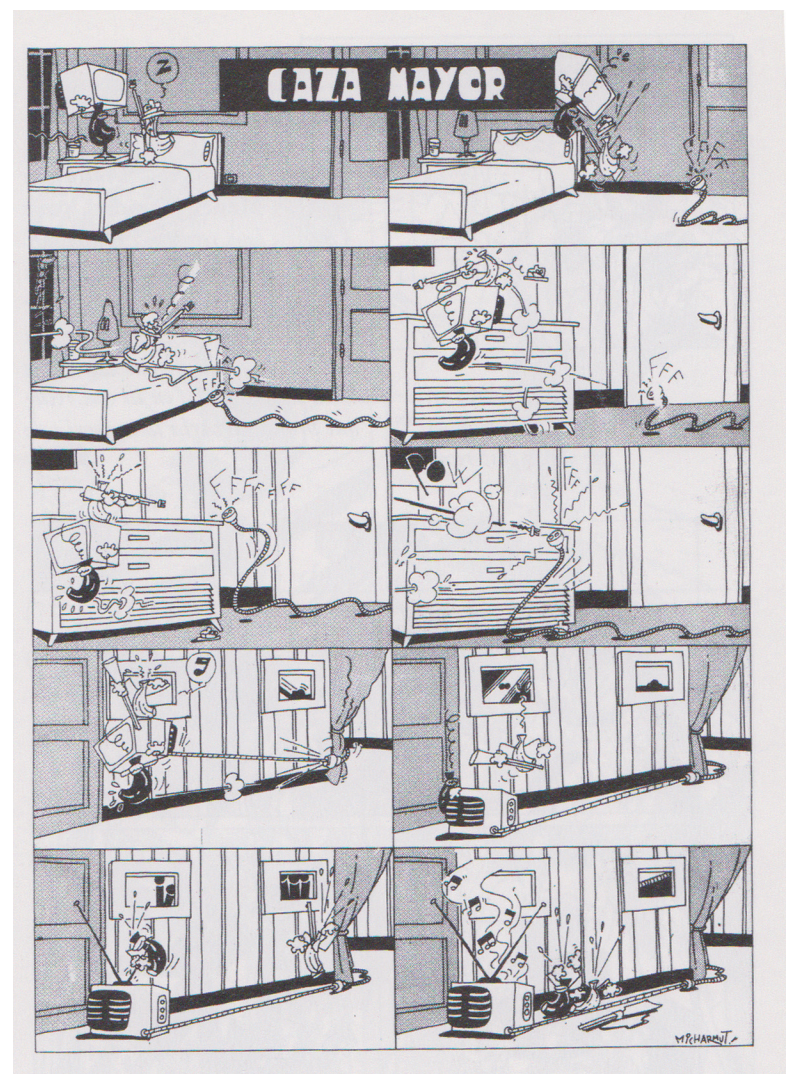

FIG. 2. “Caza Mayor”, publicada en el número 5 de Bésame $M u-$ cho (1979).

\footnotetext{
9 LLadó, F. Los cómics de la transición. Barcelona, Glénat, 2001

10 “The spanish invasión- A survey”, en The Warren Companion, RoAch, D. A. y Cooke, J. B. (Eds). Raleigh, Twomorrows publishing, 2001
} 
same $M u c h o$, pero pese a la apertura casi libertaria que se maneja por bandera de estas publicaciones, la vanguardia estética de Micharmut parece no encontrar acomodo sencillo. Sería en el quinto número de Bésame Mucho donde aparece por primera vez una historieta de este autor, África en casa, en la que sorprende por su atrevimiento temático y estilístico. En lo formal, Micharmut se atreve a establecer una correlación clara entre el entorno mutable de George Herriman y la línea definida y elegante de Coll. En lo temático, Micharmut reincide en su obsesión por lo inanimado e inórganico, dando protagonismo de sus historias a objetos: un plátano con salakov y fusil tendrá que cazar un peligroso cable eléctrico mientras una especie de berenjena porta un televisor. El referente infantil de las historietas clásicas del TBO de Coll está presente en lo temático y en lo formal, desde el uso de las onomatopeyas clásicas a los elementos cinéticos comunes o incluso la composición de la página, pero la extracción de todo elemento humano descompone el discurso infantil para establecer una sátira delirante y surrealista en la que todo elemento de la viñeta se convierte en motivo de reflexión.

Pero el movimiento de autores valencianos alcanzaría su máxima notoriedad apenas un par de años después: en 1981 la editorial barcelonesa Norma Editorial publica la revista Cairo, que con el subtítulo de "El neotebeo" busca trasladar al lector español unos postulados estéticos renovadores inspirados en el movimiento de la línea clara que en Francia lidera Joost Swarte. ${ }^{11}$ Frente al clasicismo americano que impera en las publicaciones de la editorial Toutain o la renovación del movimiento humanoide que impera en las revistas de Nueva Frontera, Cairo apuesta decididamente por los seguidores de la línea clara en Francia (con Floc'h a la cabeza, pero con la reivindicación omnipresente de Hergé o Jacobs) pero también por la producción propia aupando a primera línea a autores que tengan como elemento cohesionador a la vanguardia estética. Una condición que es cumplida claramente por los autores que se habían reunido alrededor de El Gat Pelat o Els Tebeus del Cingle y que en muy poco tiempo invadirán las páginas de la revista hasta casi monopolizarlas. Daniel Torres y Mique Beltrán abrirían la puerta a todo el grupo, hasta que en el número 18 coinciden con Mariscal, Sento Llobell y el propio Micharmut, conformando un grupo que desde la revista se bautiza como "La nueva Escuela Valenciana". ${ }^{2}$

En su paso a Cairo, Micharmut aporta historias cortas en las que se trasladan las inquietudes que estaba ejercitando en Bésame Mucho, pero aportando nuevos elementos: los seres humanos comienzan a aparecer en sus páginas, pero fuertemente deformados a través de elementos geométricos radicales, casi de abstracción, pero sin dejar de lado la constante presencia del elemento inorgánico y la incorporación del escenario cambiante heredado de Herriman. Una elección estética que se acompañará de la ausencia de diálogos, estableciendo una relación con el lector alejada, de testigo silente de las situaciones. Las historietas cortas que Micharmut publica en estas primeras colaboraciones con Cairo son ejercicios estéticos extremos sin concesiones. Sirva como ejemplo la historieta Stop, donde la composición de página se erige en clave de la historia a través de la confrontación entre la propia geometría de las viñetas y un dibujo de diseño de línea violenta, casi agresiva en su aparente linealidad. La apariencia externa del dibujo es de líneas rectas y duras, pero este aspecto se pierde al entrar en una viñeta conformada de trazos gruesos ondulantes en la mirada cercana, construyendo un contraste visual sorprendente en el que un bosque de árboles irá generando una persecución alocada en un extraño laberinto que terminará en una brillante viñeta única donde se transformará un bosque orgánico en la propia composición de viñetas de la página.

En paralelo a su debut en Cairo, Micharmut realizaría para la naciente editorial Arrebato su primera historieta larga, Dogon (1983). ${ }^{13}$ Una historia de género en la que el autor realiza evidentes concesiones sin renunciar a su personal estilo: construye una historia de corte clásica con proyecciones que desde el género negro y de aventuras, incorporando elementos del folletín clásico presentes en los populares cua-

11 Pérez del Solar, P. Imágenes del desencanto. Madrid, Iberoamericana, 2013.

12 Pons, Á., Porcel, P. y Sorní, V. Op. cit.

13 Esta obra sería el primer volumen de la colección Imposible, que recuperaba la estética de la colección Atomium58 de Magic Strip: formato pequeño, tapa dura y lomo de tela. 


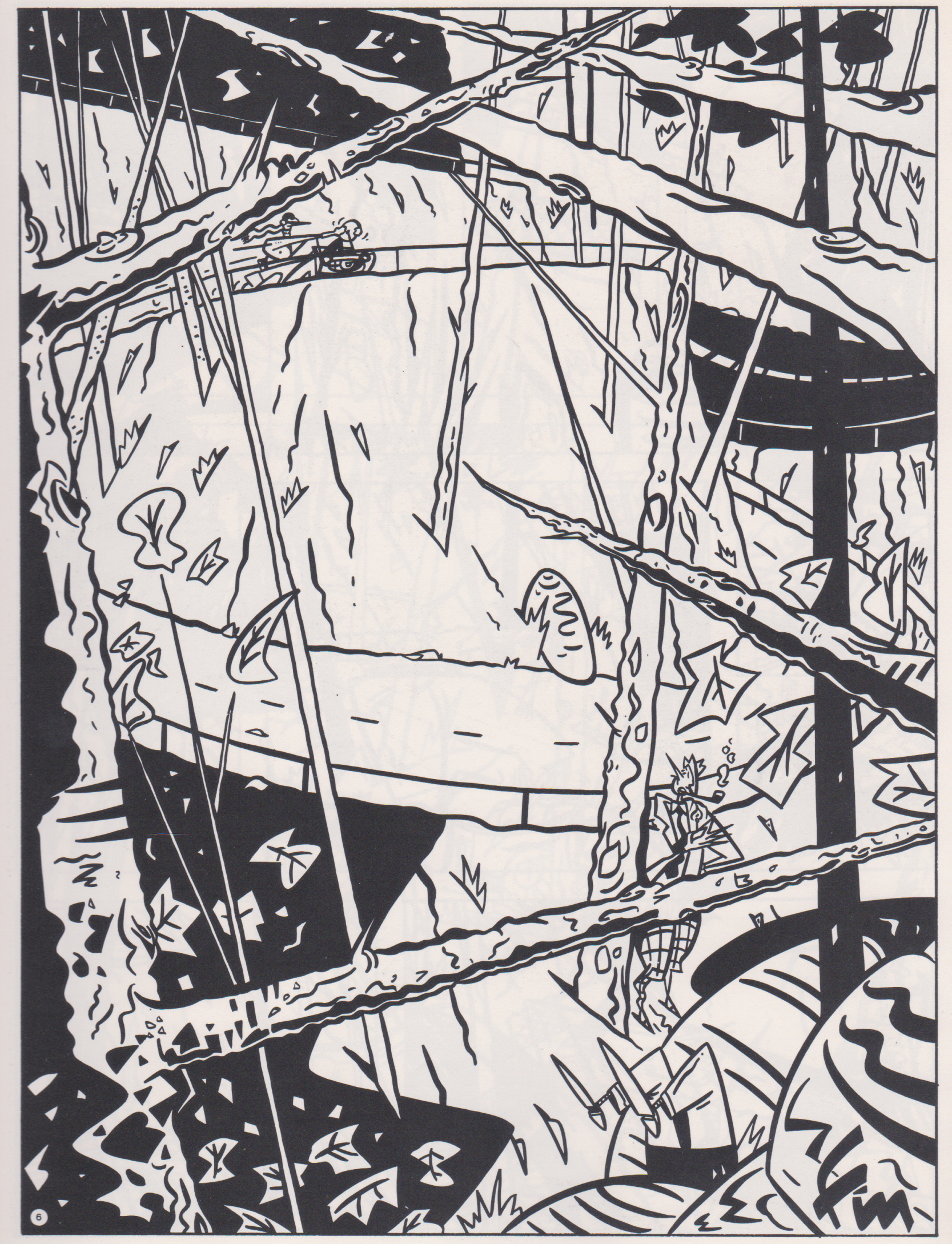

FIG. 3. Página de la historieta "Stop”, publicada en la revista

Cairo (1982). 
dernillos de aventuras de los años 50 y en las novelitas tan populares en los kioscos en la misma época, pero desde un planteamiento formal que bebe directamente de la experiencia de las historietas cortas de Cairo. Es evidente que Micharmut aprovecha la experiencia que le brinda Arrebato para detener su progresión gráfica continuada, probando nuevos recursos sobre una narrativa aparentemente más convencional en su propuesta, pero que opta por practicar su imparable libertad creativa en lo argumental. En Dogon se da inicio a la constante búsqueda que Micharmut desarrollará de la tradición narrativa que se esconde tras el folletín popular, tanto desde la perspectiva clásica que entronca con la literatura popular decimonónica como por la traslación que esta tiene a la cultura popular a través del cuadernillo y la novela popular. En ese sentido, hay que destacar la fuerte carga simbólica del diseño de escenarios y personajes, que bebe directamente de la iconografía popular para ser reinterpretada a través de su personalísimo estilo.

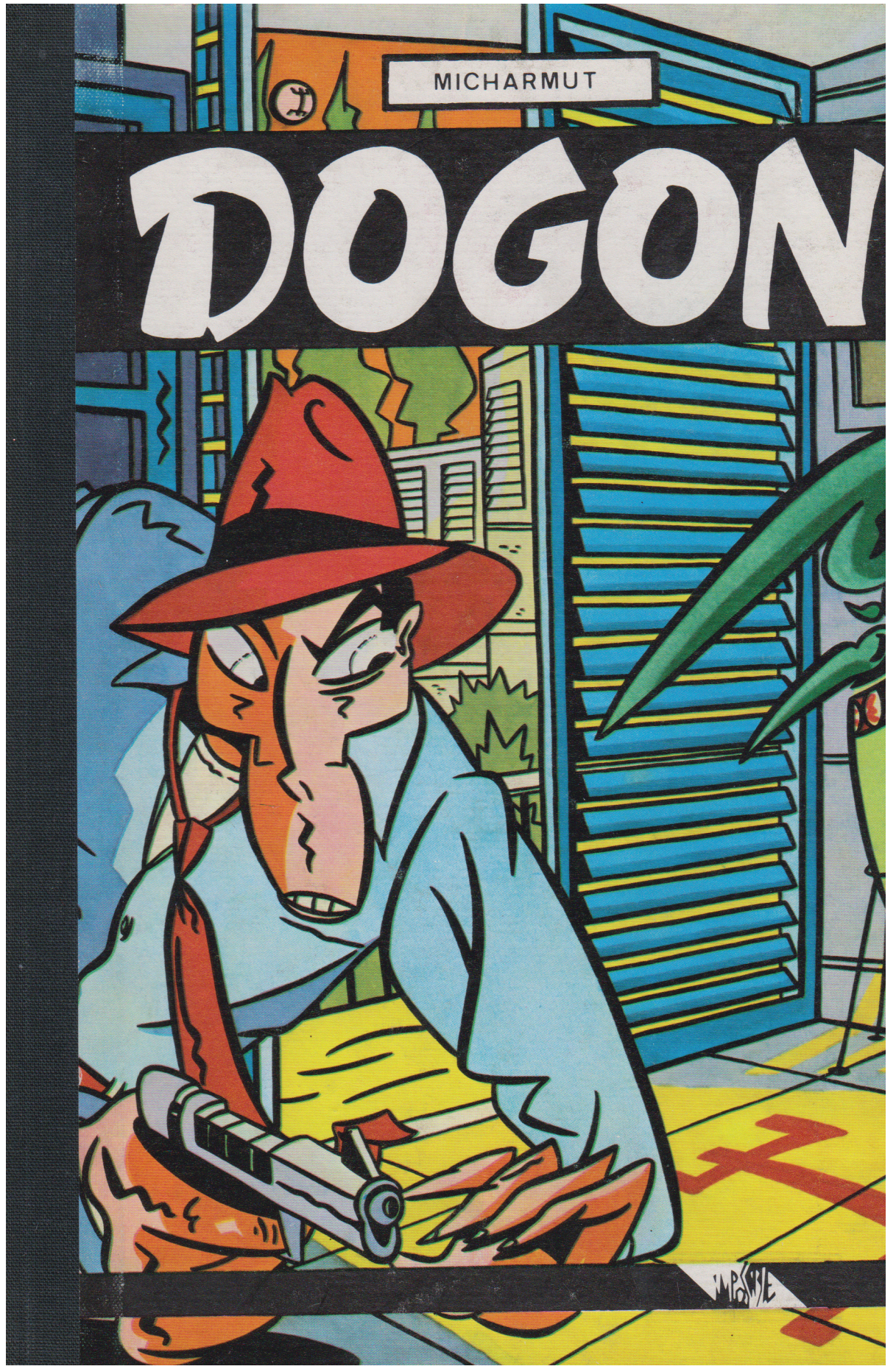

FIG. 4. Portada de Dogon, primer número de la colección Misión Imposible de la Editorial Arrebato (1983). 


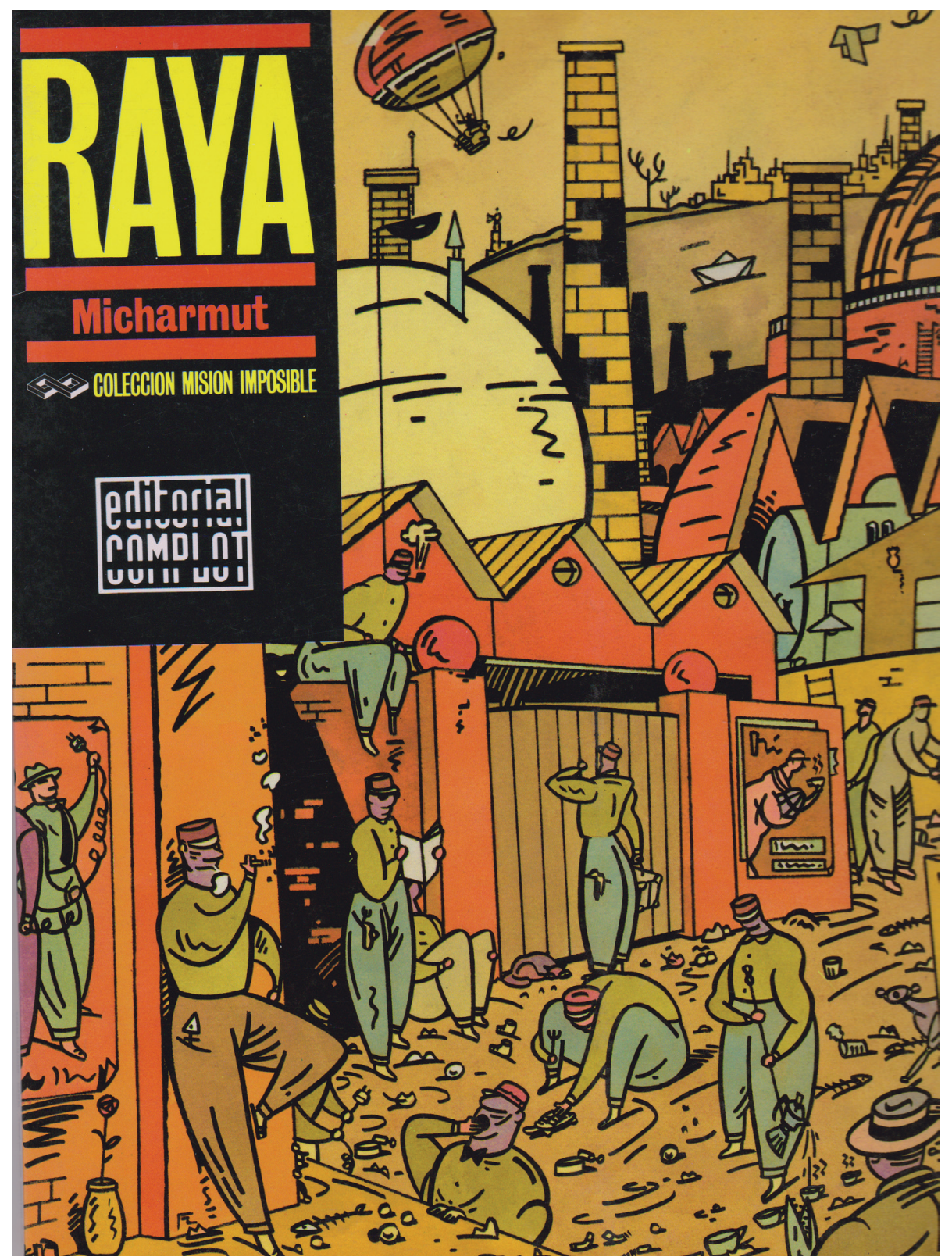

FIG. 5. Portada de la edición recopilatoria de Raya (Editorial Complot, 1987).

Tras estas experiencias, Micharmut comenzaría a serializar en la revista Cairo la primera de sus grandes obras maestras: Raya (1983). Tras los años de aprendizaje, el autor estaba en condiciones de plasmar por fin un ideario personal, una obra que estableciera sin ambages todas las claves y principios de un discurso ideológico y estético que estructurará y guiará su obra posterior. Raya nace con una premisa argumental a medio camino entre Capra y Chandler: un detective en la ciudad del Infierno, dedicado a investigar los más extraños casos que ocurren en el averno entre arcángeles, dioses y demonios. Una excusa para poder analizar sin fronteras ni prejuicios todos sus planteamientos previos, con un estilo gráfico que ya está plenamente definido, heredero de una abstracción rotunda que interpreta la figura humana para sintetizar su expresividad en términos de trazo, en la confrontación de lo inanimado como geométrico de línea recta y fina y una organicidad que se revela como curva, de trazo variable y sinuoso. Un estilo construido desde la modernidad formal que permitirá el contraste con un contenido que lanza su mirada al pasado, a la recuperación de las narrativas más clásicas de la novela y la historieta. Las historias cortas de Raya alternarán el episodio de adscripción al género policiaco con otros de voluntad consciente anecdótica. En los primeros, Micharmut aprovechará la simbología e iconografía de la narración popular; en 
los segundos, la del cómic clásico infantil definido por TBO o Pumby. En ambos casos, su aproximación permite obtener una lectura sorprendente que se aleja de toda preconcepción para encontrar su espacio personal. Sirva como ejemplo perfecto de esta ideología creativa el episodio "Migrañas infernales": Micharmut retoma la composición de página en largas viñetas horizontales que usaba en ocasiones Coll junto a su característica viñeta circular para establecer un diálogo entre dos acciones. En la primera, una conversación telefónica anodina para reclamar dos botellas de alcohol más que termina en inesperada trama. En la segunda, una habitación desordenada en mutación continuada que será ordenada por una legión de diminutos soldados babilonios. El surrealismo inherente al planteamiento pronto encuentra un ritmo propio inesperado, en el que de nuevo los objetos toman vida propia para componer un escenario mutable totalmente hipnótico para el lector. Una versión posmoderna del cuento clásico del Zapatero y los duendecillos de los hermanos Grimm que dinamita el concepto tradicional de narrativa, eludiendo toda clasificación final. La anécdota intrascendente se traduce en pura experiencia estética sin límites donde cabe el análisis y la reflexión.

Raya se erige como punto de inflexión total en la evolución del autor y, además, del medio. El atrevimiento vanguardista de la obra de Micharmut solo puede ser comparado al de la generación de autores nacida durante los años 30 en la prensa satírica, desde Tono a Mihura, pero sobre todo establece el nacimiento de un autor maldito. La obra de Micharmut se aleja totalmente de los cánones de la época y se adentra en un gueto de incomprensión por los lectores. Pese a ser muy apreciado por una parte de la crítica de su momento, sus ideas son demasiado avanzadas para ser consideradas por el público que le da la espalda y, con él, los editores. Ese malditismo se combinaría con el crash que vive el fenómeno de las revistas de cómic de autor durante el segundo lustro de los años 80 para alejarlo de los circuitos habituales de publicación, lo que le obliga a refugiarse en el diseño gráfico.

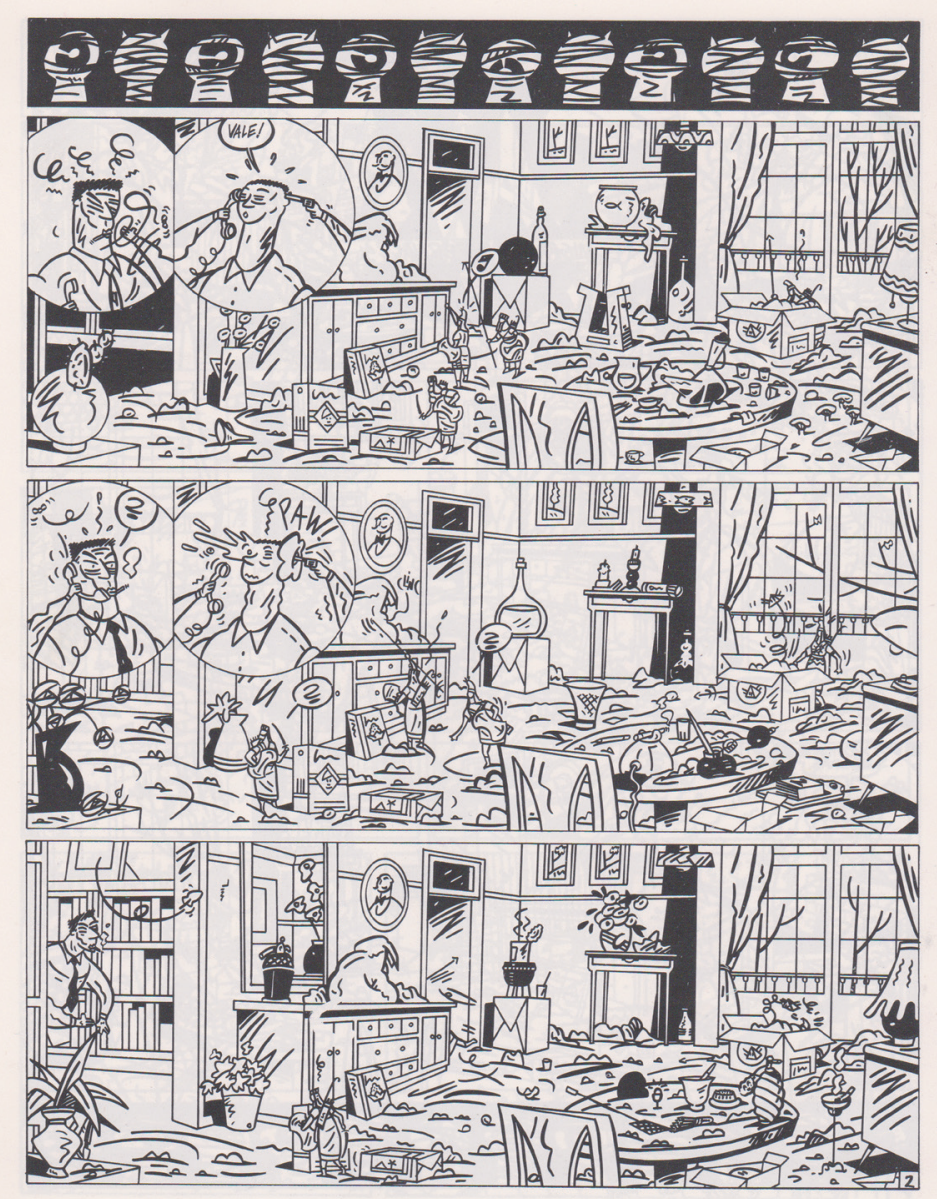

FIG. 6. Página de "Migrañas infernales", parte de la serie Raya (Revista Cairo, Norma Editorial, 1984). 


\section{Maldito, pero de principios intactos}

En los años 90 Micharmut colaboraría en el relanzamiento de la revista infantil Camacuc con la serie Pip, su primera obra larga en color. Fiel a sus principios, crearía una historia de pequeños insectos que viven sus aventuras a reflejo de las que dibujaban Nin, Karpa o Sanchis en Pumby y Jaimito. ${ }^{14}$ Pero a diferencia de la universalidad de aquellos, Micharmut lleva a sus personajes a los bosques del Alto Palancia, su comarca natal, para desarrollar un homenaje no solo a sus lecturas infantiles, sino a sus propias vivencias. Aprovecha el color para hacer recorrido por las vegetaciones y caminos, por los ríos y las fuentes de $\mathrm{Na}-$ vajas, Caudiel o Montanejos. No le hace falta nombrar los pueblos, son reconocibles por el cromatismo, por las formas y por el aroma que supuran las viñetas. Un canto a su tierra que, de nuevo, era completamente incomprendido.

Idéntico camino siguió Marisco, una lujosa recopilación editada por La General de sus trabajos en fanzines en los 80 y de su labor como ilustrador, que pese a la brillantez de sus hallazgos se prejuzgó por su calificación de autor maldito.

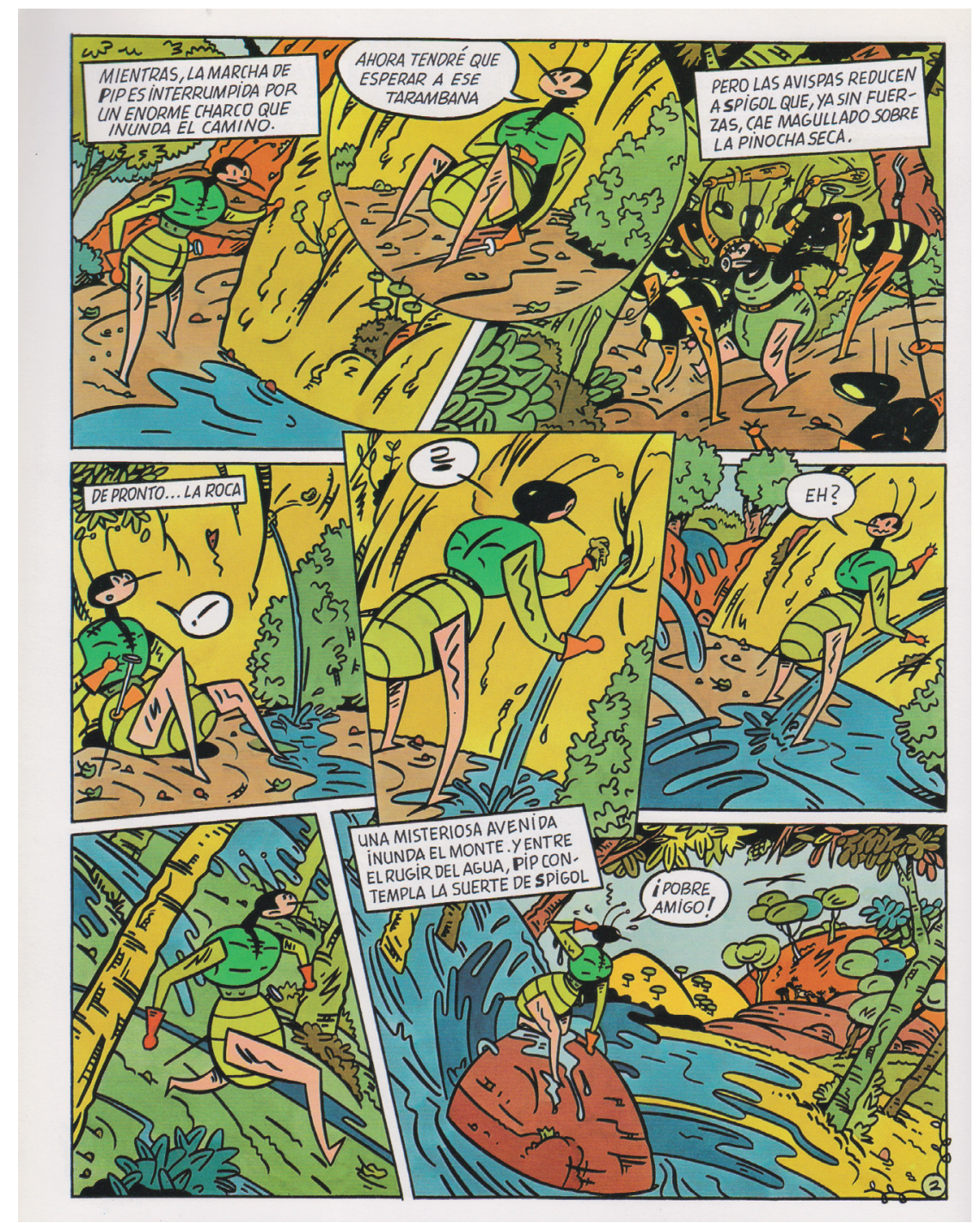

FIG. 7. Página de "Pip", publicada originariamente en la revista

Camacuc (1990) y recopilada posteriormente en monografía por Edicions de Ponent, en la que se observan lugares que recuerdan la zona del Alto Palancia en Castellón.

\footnotetext{
${ }^{14}$ Josep Sanchis fue el creador de Pumby. Nin creó el famoso personaje de Trompy para la revista Pumby y Karpa fue el creador de Jaimito. Pons, Á., Porcel, P. y Sorní, V. Op. cit.
} 
Pero todas estas consideraciones externas no afectaron a Micharmut, que siguió emperrado en su labor de descubrimiento de nuevos límites formales para el lenguaje de la historieta, como demostraría en 1995 con Veinticuatro horas. La editorial valenciana Edicions de Ponent había iniciado recientemente la colección Mercat con una voluntad rompedora: libros lujosamente editados a contracorriente de un momento monopolizado por la edición de cuadernillos en grapa, evitando la corriente imperante del género superheroico y sus variantes para adentrarse en otras vías temáticas, pero siempre desde una perspectiva creativa basada en la libertad autoral, en una concepción del cómic de autor que recuperaba los intentos pioneros de la década anterior. Bajo esos presupuestos, y tras el monumental comienzo de la colección que supuso Monólogo y alucinación del gigante blanco, de Max, el autor valenciano aborda una obra que lleva el lenguaje de la historieta a todos sus extremos, descomponiendo 24 horas de la vida una ciudad en todos sus componentes mínimos. Micharmut actuará a modo de testigo mudo que se mueve por las calles, por los tejados, por el subsuelo, por todos los recovecos de la ciudad para plasmar una vida desconocida. Una especie de foto fija que se va animando para demostrar la existencia de seres y formas que nunca parecieron estar ahí, extrayendo reflexiones sobre el paso del tiempo en una sociedad que actúa como colmena inconsciente a través de una propuesta gráfica innovadora. Cada "fotografía", cada escena, es planteada desde una narrativa diferente, desde el homenaje clásico al TBO a ilustraciones a doble página, desde el texto a pie de viñeta al modo de las aucas y aleluyas a una composición de viñeta y página que oculta formas y rostros. Todas sus claves anteriores vuelven con fuerza: la apropiación de los espacios en blanco por la línea, la obsesión por lo inanimado, la reivindicación de cualquier recoveco olvidado de la cultura popular, la narración paralela, la autoconsciencia propia e independiente de los escenarios... Pero por fin, encuentran un sentido, una unión perfecta para desarrollar un discurso único, para trasladar un mensaje definido en el que el lector debe tomar parte decisiva desde una interpretación que en ningún momento deja lugar a lo evidente. Toda opción es posible, toda solución obvia es evitada en una propuesta que avanza la que será su obra magna, Sólo para moscas.

Pero toda la fuerza creativa que se plasma en Veinticuatro horas solo sirve para alimentar más todavía la imagen de malditismo del autor, que se ve definitivamente abocado a la exclusión. Pese a que la aparición de editoriales como De Ponent, Inrevés o Sins Entido recuperan un discurso autoral comprometido con la renovación estética perdido desde hace años en España y abren el paso a nuevo acercamiento social a la historieta que acepta por fin el cambio de formas de consumo y, sobre todo, la posibilidad del medio como lenguaje artístico que permite la exploración de cualquier temática, la obra de Micharmut no encuentra fácil ubicación. En la década siguiente, apenas aparecen dos propuestas con su firma: La noche de la rata (Edicions de Ponent), en el que se adentra en la traslación de la experiencia lectora del joven que disfrutaba de las revistas de los años 50 mediante la emulación de una de aquellas publicaciones, en una simulación que actúa que caballo de Troya de las radicales propuestas de Micharmut. Juega con temáticas y grafismos, con la publicidad e incluso con los correos lectores, ensayando la que luego será la experiencia colectiva de los Almanaques. ${ }^{15}$ Junto a esta pequeña edición, la misma editorial publicaría Arf, un recopilatorio de pequeñas historias publicadas en diferentes medios durante esos años perdidos en el ostracismo de lo maldito, pero que evidencia la espectacular experimentación formal que el autor ha realizado durante casi veinte años, siempre en el filo de la navaja, siempre en busca del camino inexplorado.

\section{Moscas digitales}

El aura de autor complicado que rodeaba a Micharmut desde sus inicios favoreció que su visibilidad se fuera reduciendo. Pese a la fidelidad que encontró en Edicions de Ponent, dispuesta a correr el riesgo de sus ediciones a sabiendas de su nula rentabilidad, Micharmut no conseguía que su obra saliera de

\footnotetext{
15 Se publicarían dos almanaques: Almanaque comestible (2009) y Almanaque del fin del mundo (2011), ambos editados por Edicions de Ponent y con colaboraciones de autores como Keko, Cifré, Txemacantropus, Jorge García, Gustavo Rico, F.H. Cava o Pablo Auladell.
} 
unos círculos iniciados. Su visibilidad era nula ante la miopía de un mercado que prima otros factores como elemento de juicio en la valoración final de una obra, que deja de lado la experimentación formal y la condena como herética de lo establecido. Una rueda viciada que encontró salida en los medios digitales: ante la imposibilidad de publicar en papel, Micharmut encontró en la universalidad de internet una salida a su continua creatividad. En enero de 2008 creó el blog Sólo para moscas, ${ }^{16}$ un espacio de experimentación sin límites donde fue dando salida a sus inquietudes y donde perdió las pocas fronteras que todavía se autoimponía. Sabedor de su malditismo, Micharmut limitaba su creatividad por la consciencia de la dificultad de dar salida editada a su obra. Pero liberado del papel, de la necesidad de un editor, encontrará en internet un aliado inesperado, donde tan solo se verá restringido por un desconocimiento técnico que el tiempo irá remediando. Poco a poco, Sólo para moscas comienza a crecer con series paralelas, con textos e ilustración, con recuperación de antiguas obras, pasando de cajón de sastre digital a configurarse un espacio personal único donde la historieta y la cultura popular se erigen como ejes absolutos. Nuevas series como "13 Rue Babilonia", "Chimeneas", "Retratos al minuto", "Orugas" o "Pat \& Murphy", recuperan todas sus claves pasadas con fuerza inusitada: lo inanimado pasa de nuevo a obtener protagonismo adquiriendo fuerza orgánica, la línea como elemento cohesionador de una página que toma voz propia, los objetos reconvertidos, la transformación sempiterna, el horror vacui como pretexto de la mutación por acumulación... En cierta medida, las moscas digitales debían ser herederas del espíritu de Veinticuatro horas, testimonios mudos de una urbanidad interpretada, pero su progresión impone una evolución que las lleva a transformarse en afilada disección de la sociedad actual.

\section{sólo para moscas}

\begin{tabular}{|c|c|c|c|c|c|}
\hline FRONT PAGE & BUZóN & & SECCIONES & & \\
\hline Entosicol & & 67 & $=$ & \multirow{5}{*}{\multicolumn{2}{|c|}{ 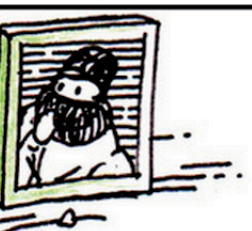 }} \\
\hline \multirow{3}{*}{\multicolumn{2}{|c|}{ Hombige: }} & 68 & 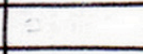 & & \\
\hline & & 69 & $=$ & & \\
\hline & & 70 & & & \\
\hline $27 z=6$ & & 71 & & & \\
\hline
\end{tabular}

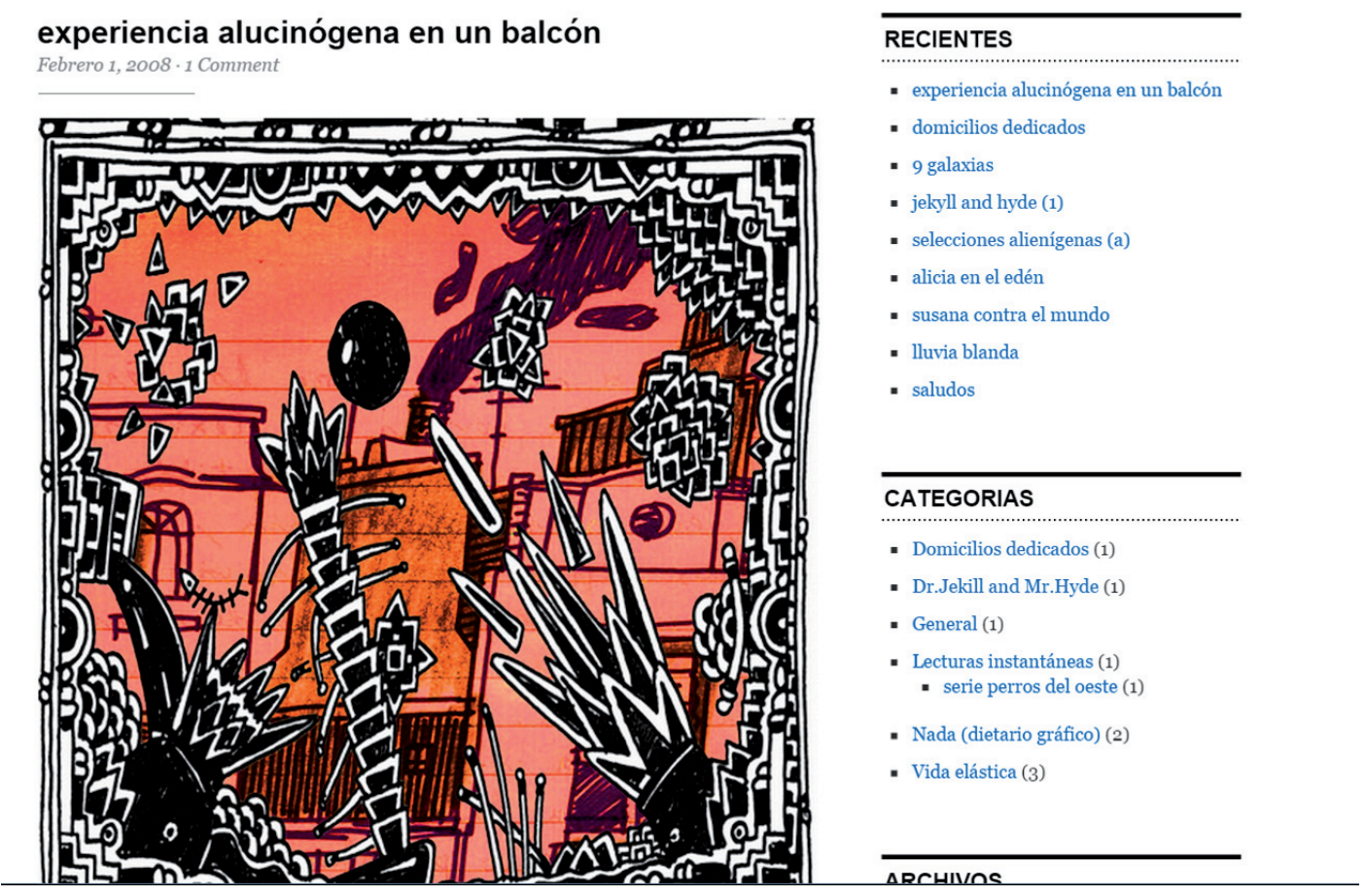

FIG. 8. Impresión de pantalla del blog Sólo para moscas.

16 Se puede consultar en http://soloparamoscas.wordpress.com 
En 2012, el largo camino de Sólo para moscas se transfiguró para encontrarse de nuevo con el papel, en una nueva edición donde la obra digital pierde su constante fluir para encontrar una nueva lectura, fiel a los principios del autor, pero profundamente distinta, una mirada alterada que proporciona una nueva obra donde cada página obliga al análisis detenido a la búsqueda de historias ocultas tras el maremágnum gráfico. Las páginas de la edición en papel se convierten así en un caleidoscopio que varía constantemente según se mire. En trampantojos continuos donde los paisajes urbanos escondes estados y sentimientos tras retratos escondidos, en pictografías jeroglíficas que cuentan historias tras coreografías geométricas, en domicilios palindrómicos que rompen la simetría con pequeños detalles que obligan a la reflexión de la extrañeza. Continuos retos a un lector al que no se deja posibilidad de escape, que debe entrar a trapo en el juego propuesto a sabiendas de la mirada continua de un autor escondido pero de presencia omniscente, que incluso en determinados momentos vuelve su mirada hacia el lector a través de "Pat y Murphy" para escudriñarle asomándose a una ventana de la cuarta pared para ojear sin vergüenza a un lector que difícilmente podrá sostener esa mirada de ojos que no pestañean, pese a ser los únicos que entablarán diálogo con el lector.
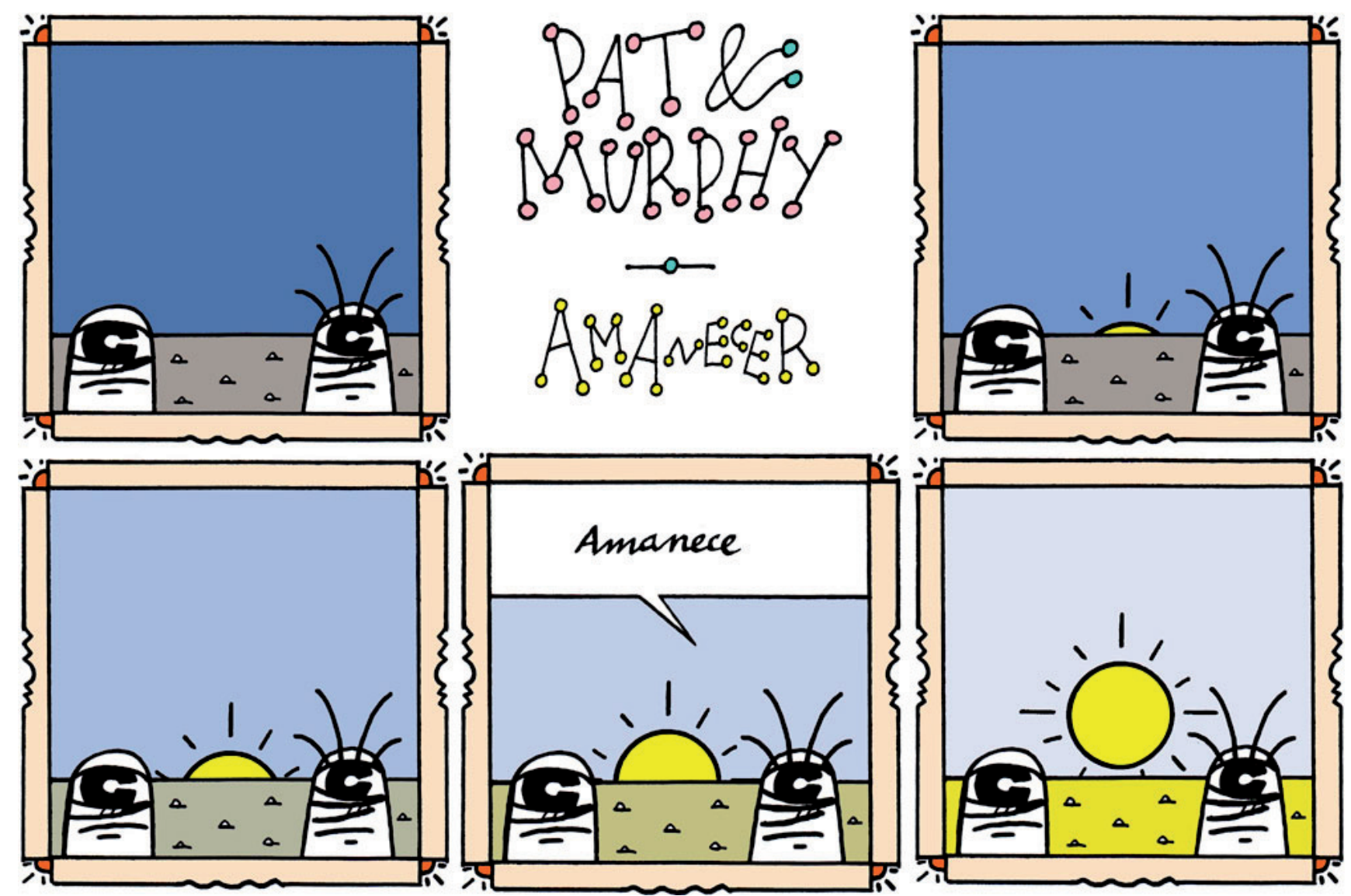

Figura 9. "Pat \& Murphy", una de las series fijas de Sólo para moscas, en la que los personajes se dirigen continuamente al lector.

El alcance de Sólo para moscas es inabarcable: para el lenguaje de la historieta es un catálogo infinito de posibilidades de exploración de la narrativa gráfica, que es capaz de transitar entre la referencia rendida a la cultura popular más olvidada y la abstracción pura de la secuencialidad gráfica. Para una sociedad en crisis que se debate entre la indignación y la resignación desencantada, un retrato inmisericorde de sus penas y desdichas, de esos residuos sentimentales y anímicos que componen una basura que nunca se recicla ni se enseña, que solo las moscas de papel de Micharmut son capaces de descubrir y sacar a la luz. 